\title{
Clinical Study \\ Outcome Assessment of the Marshall Coughing Test during Cervix Reposition Maneuver in Women with Urinary Stress Incontinence with/without Genital Prolapse
}

\author{
Vesna Antovska \\ Department for Urogynaecology and Pelvic Floor Disorders, University Clinic for Gynaecology and Obstetrics, Medical Faculty, \\ University "Saint Cyril and Methodius", Vodnjanska 17, 1000 Skopje, Macedonia \\ Correspondence should be addressed to Vesna Antovska, vantovska@yahoo.com \\ Received 22 November 2011; Accepted 11 December 2011 \\ Academic Editors: C. E. Constantinou and M. Salido \\ Copyright ( $) 2012$ Vesna Antovska. This is an open access article distributed under the Creative Commons Attribution License, \\ which permits unrestricted use, distribution, and reproduction in any medium, provided the original work is properly cited. \\ Objectives. Outcome assessment of the Marshall coughing test (MT) during cervix reposition maneuver (CRM) in women with \\ urinary stress incontinence (USI) with/without genital prolapse (GP). Study Design. 268 patients, divided into USIg $(n=132)$ with \\ isolated USI and USIGPg $(n=136)$ with USI and GP stage I/II, additionally divided into USIGP(A) $(n=78)$ with USI and GP \\ stage I and USIGP(B) $(n=58)$ with USI and GP stage II, were evaluated with pelvic organ prolapse quantification (POPQ), MT, \\ and CRM. Results. (a) 7.58\% had (+) MT with CRM in USIg; (b) in up to 96.15\% MT became negative during CRM in USIGP(A); \\ (c) in 51.72\% MT became positive only during CRM, as a sign for occult USI in USIGP(B); (d) point Aa (POPQ), which is bladder \\ neck $(\mathrm{BN})$ projection on the anterior vaginal wall, was situated higher in rest position (RP), but moved lower during the Valsalva \\ maneuver $(\mathrm{VM})$ in USIg versus USIGPg $(P<0.05)$. Conclusion. CRM could be useful arm in selection of $(1)$ patients with isolated \\ USI and great chance for postoperative failure; (2) patients with USI+GP stage I, who need GP repair during antistress surgery; \\ (3) patients with USI + GP stage II, who need antistress procedure during vaginal hysterectomy.
}

\section{Introduction}

Women with genital prolapse (GP) may be continent paradoxically, as a result of urethral kinking or compression, but after repair of GP, $22-80 \%$ of patients will present de novo urinary stress incontinence (USI) [1]. These women have occult USI and can be preoperatively identified by performing the barrier test, which is actually a stress test to determine whether urine leakage occurs during GPreposition. This test can be performed in several different ways, such as using a pessary, vaginal pack, or Sims' speculum or performing the cervix reposition maneuver (CRM), which is simple imitation of postoperative pelvic organ position with grasping the cervix with tenaculum and pushing it in upwards/backwards direction to the promontorium. The barrier test can also be performed during urodynamic investigation in sitting position with the bladder at maximum cystometric capacity, because if it is performed at a lower bladder volume, the prolapse may still mask USI. Klutke and Ramos [2] suggested that a negative reposition test is reliable in the prediction of patient who will be stress continent after prolapse repair. Gordon et al. [3] reported that $50 \%$ of clinically continent women with severe pelvic organ prolapse, who had a preoperative positive barrier test, experienced de novo USI after prolapse repair. Lecuru et al. [4] in their series of 203 abdominal correction of GP reported 86.7 to $100 \%$ anatomically good long-term results, but only 53.3 to $80.5 \%$ functionally good. In a study of 191 patients with GP [5], in 50\% this prolapse was combined with USI. Vaginal prolapse recurred after 4 and 12 months in 4 and 6\% of cases, respectively, but up to $31 \%$ still complained of USI 4 months after the operation. Morley and DeLancey [6] in 57 patients with sacrospinous suspension had $12.28 \%$ recurrent vaginal prolapse and $15.79 \%$ postoperative USI. Hewson [7] had only $60 \%$ cure of USI with additional buttressing sutures and only 35\% improvement of intercourse. Maher et al. [8], in order to determine the effects of many different surgeries used in the management of pelvic organ prolapse, searched 
the Cochrane Incontinence Group Specialised Register ( 9 February 2009) and reference lists of relevant articles. According to their analysis of 40 randomized controlled trials which included 3773 women, the continence surgery at the time of prolapse surgery in continent women did not significantly reduce the rate of postoperative stress urinary incontinence (RR 1.39, 95\% CI 0.53 to 3.70; random-effects model).

The central question in the preoperative evaluation of women with USI in presence or absence of GP is to estimate functional outcome once the anatomy is corrected. It is well documented that correction of the anatomy can decrease resistance to the urethra, thereby unmasking intrinsic sphincter deficiency [9]. On the other hand, the different antistress procedures in patients with USI without GP also can result in postoperative failure, perhaps due to vertical pelvic organ position. Different authors report different failure rate, from more than $30 \%$ to less than $10 \%$ [10-12]. Nevertheless, the cure rate shows a decreasing trend over the time. So, within the first year of treatment, the overall continence rate is approximately $85-90 \%$, but after 5 years, approximately $70 \%$ of patients can expect to be dry [13]. According to the integral theory of continence of Ulmsten, Petros, and Woodman [14, 15], the forward muscle force of $\mathrm{m}$. pubococcygeus stretches the vagina forwards against the pubourethral ligament to close the urethra behind, and backward forces stretch the upper vagina and bladder base backwards and downwards in a plane around the pubourethral ligament to close off the proximal urethra. In patients with vertical pelvic organ position, perhaps this mechanism does not work quite effectively.

\section{Material and Methods}

2.1. Eligibility Criteria for Participants. Presence of USI with or without GP stage I or II (according to the POPQ system) [16].

2.2. The Setting, Location, and Timing: Where and When the Data Were Collected. The Department for Urogynecology and Pelvic Floor Disorders in the Clinic of Gynecology and Obstetrics, Medical Faculty of the "Saint Cyril and Methodius" University, in Skopje in the period from the 1st of January 2010 to the 31 st of December 2010. The study was designed according to the CONSORT statement [17].

2.3. Precise Details of the Interventions for Each Group: How and When They Were Actually Administered. The experimental arms are (1) coexisting presence of GP stage I/II and USI, that is, USIGP group (USIGPg) $(n=136)$ and (2) presence of USI without GP, that is, USI group (USIg) $(n=132)$. The study was approved by the local research ethics committee of the Macedonian Association of Gynecologists and Obstetricians. The clinical assessment of patients was performed by the author of this paper. The study was a prospective observational study with no allowance for patient preference.

2.4. How Sample Size Was Determined and the Method Used to Generate the Random Allocation Sequence, Including
Details of Any Restriction. Every postmenopausal patient with isolated USI, or with USI and GP stage I/II, admitted to our Department in the above-mentioned period, was assessed for eligibility $(n=278)$. Ten patients were excluded from the study because they were unwilling to participate. So, 268 patients were randomised, and all of them completed the study. After they underwent the complete urogynecologic examination according to our Urogynecologic Protocol, they were divided into two groups: USIGPg $(n=136)$ with GP and USI and USIg $(n=132)$ only with USI. Additionally, USIGPg was divided into two subgroups: $\operatorname{USIGP}(\mathrm{A})(n=78)$ with GP stage I and USIGP(B) $(n=58)$ with GP stage II. All participants were aware of group assignment. All subjects were given an explanation of the study, and written informed consent was obtained.

2.5. Specific Objectives and Hypotheses. The purpose of the study was an outcome assessment of the Marshall coughing test (MT) during cervix reposition maneuver (CRM) in lithotomic position in patients with USI with/without GP. The hypotheses were as follows: (1) about $10 \%$ of patients with isolated USI have positive MT only in upright position, (2) about $10 \%$ of patients with isolated USI have positive MT during CRM; (3) more than $80 \%$ of patients with manifest USI and GP stage I have negative MT during CRM; (4) about $20 \%$ of patients with USI and GP stage II have positive MT during CRM, as a sign of occult USI.

2.6. Clearly Defined Primary and Secondary Outcome Measures: All Methods Used to Enhance the Quality of Measurements.

(1) Demographic data, such as age, duration of postmenopausal age, parity, BMI, and occupation, were evaluated.

(2) Complete evaluation for urinary incontinence: a structured questionnaire for urinary symptoms based on the International Continence Society recommendation [18]; multichannel urodynamic examination: retrograde provocative multichannel urethrocystometry, passive and dynamic urethral pressure profilometry, cough and the Valsalva leak point pressure, and simple uroflowmetry with postvoid residual urine volume; MT in upright and lithotomic position, as well as lithotomic position with artificial cervix reposition that is, cervix reposition, maneuver (CRM) for detection of occult USI, after bladder filling with $300 \mathrm{~mL} \mathrm{3 \%} \mathrm{boric} \mathrm{acid.}$

(3) Complete evaluation for GP: a structured questionnaire and pelvic organ prolapse quantification (POPQ) during pelvic examination performed in the supine position in a birthing chair in rest position (RP) and while performing the Valsalva maneuver (VM) with maximal effort. The bladder was empty by catheterization and rectum too, by morning defecation.

2.7. Statistical Methods. The Student's paired test was used for comparing the demographic data and POPQ and its 
TABLE 1: Demographic data: age, duration of the postmenopausal age, parity, body mass index (BMI), and ocupation in USIGPg $(n=136)$ and USIg $(n=132)$.

\begin{tabular}{|c|c|c|c|}
\hline Variable & $\operatorname{USIGPg}(n=136)$ & USIg $(n=132)$ & $t / \chi^{2}$ \\
\hline Age (years) $($ mean $\pm S D) 1$ & $61.3 \pm 4.5$ & $52.2 \pm 5.2$ & 1.32 \\
\hline $\begin{array}{l}\text { Duration of postmenopausal period (years) } \\
(\text { mean } \pm \text { SD) } 1\end{array}$ & $13.4 \pm 3.3$ & $3.7 \pm 3.1$ & $2.96^{(*)}$ \\
\hline Parity $($ mean $\pm S D) 1$ & $3.2 \pm 0.9$ & $2.1 \pm 0.6$ & 0.60 \\
\hline Body mass index $($ mean $\pm S D) 1$ & $28.3 \pm 4.1$ & $34.3 \pm 4.2$ & 1.02 \\
\hline Factory worker 2 & $17 / 136$ & $29 / 136$ & $6.33^{(\dagger)}$ \\
\hline Farmer 2 & $42 / 136$ & $25 / 132$ & $4.49^{(\dagger)}$ \\
\hline Clerk/teacher 2 & $8 / 136$ & $28 / 132$ & $14.93^{(\ddagger)}$ \\
\hline Housewife 2 & $25 / 136$ & $35 / 132$ & 3.05 \\
\hline Retired person 2 & $44 / 136$ & $15 / 132$ & $16.03^{(\ddagger)}$ \\
\hline
\end{tabular}

(1) Student's paired test: ${ }^{(\dagger)} P<0.05 ; \quad{ }^{(*)} P<0.01 ;{ }^{\left({ }^{\ddagger}\right)} P<0.001 .(2)$ Mantel-Haenzel's $\chi^{2}$ test with df of $1:{ }^{(\dagger)} P<0.05 ; \quad{ }^{(*)} P<0.01 ; \quad{ }^{(\ddagger)} P<0.001$.

TABLE 2: Quantitative description of pelvic organ position (POPQ) with anatomic landmarks in USIGPg $(n=136)$ and USIg $(n=132)$.

\begin{tabular}{|c|c|c|c|c|c|c|c|c|}
\hline \multirow{3}{*}{ POPQ } & \multicolumn{2}{|c|}{ Rest position } & \multicolumn{2}{|c|}{ Valsalvas maneuver } & \multirow{3}{*}{$\begin{array}{c}t_{1} \\
1-2\end{array}$} & \multirow{3}{*}{$\begin{array}{c}t_{2} \\
3-4\end{array}$} & \multirow{3}{*}{$\begin{array}{c}t_{3} \\
1-3\end{array}$} & \multirow{3}{*}{$\begin{array}{c}t_{4} \\
2-4\end{array}$} \\
\hline & $\begin{array}{c}\text { USIGPg } \\
(n=136)\end{array}$ & $\operatorname{USIg}(n=132)$ & $\begin{array}{c}\text { USIGPg } \\
(n=136)\end{array}$ & $\operatorname{USIg}(n=132)$ & & & & \\
\hline & $(1)$ & $(2)$ & (3) & (4) & & & & \\
\hline $\mathrm{Aa}(\mathrm{cm})$ & $-1.23 \pm 0.66$ & $-1.56 \pm 0.78$ & $-2.39 \pm 0.68$ & $-0.80 \pm 0.44$ & 0.32 & $1.97^{\dagger}$ & 1.23 & 0.85 \\
\hline $\mathrm{Ba}(\mathrm{cm})$ & $-0.99 \pm 0.88$ & $-1.43 \pm 0.57$ & $+0.89 \pm 0.84$ & $-0.33 \pm 0.24$ & 0.50 & 1.39 & 0.55 & 1.79 \\
\hline $\mathrm{C}(\mathrm{cm})$ & $-1.56 \pm 1.11$ & $-7.24 \pm 0.25$ & $+0.55 \pm 1.23$ & $-5.12 \pm 0.88$ & $5.00^{\ddagger}$ & $3.75^{\ddagger}$ & 1.27 & $2.53^{*}$ \\
\hline $\mathrm{D}(\mathrm{cm})$ & $-4.83 \pm 1.36$ & $-7.55 \pm 0.77$ & $-4.19 \pm 1.22$ & $-5.86 \pm 0.99$ & 1.74 & 1.06 & 0.35 & 1.35 \\
\hline $\mathrm{Bp}(\mathrm{cm})$ & $-2.22 \pm 0.45$ & $-2.75 \pm 0.55$ & $-1.10 \pm 0.97$ & $-2.48 \pm 0.66$ & 0.75 & 1.18 & 1.05 & 0.31 \\
\hline Ap $(\mathrm{cm})$ & $-2.00 \pm 0.99$ & $-2.75 \pm 0.55$ & $-1.10 \pm 0.97$ & $-2.48 \pm 0.66$ & 0.66 & 0.18 & 0.65 & 0.31 \\
\hline $\mathrm{gh}(\mathrm{cm})$ & $4.67 \pm 0.95$ & $3.74 \pm 0.99$ & $5.11 \pm 0.69$ & $4.11 \pm 0.89$ & 0.68 & 0.89 & 0.38 & 0.28 \\
\hline $\operatorname{tvl}(\mathrm{cm})$ & $4.51 \pm 1.12$ & $7.33 \pm 0.55$ & $3.84 \pm 0.87$ & $5.58 \pm 0.68$ & $2.27^{*}$ & 1.58 & 0.47 & 1.76 \\
\hline $\mathrm{pb}(\mathrm{cm})$ & $2.18 \pm 0.46$ & $2.67 \pm 0.52$ & $2.16 \pm 0.77$ & $2.45 \pm 0.78$ & 0.71 & 0.27 & 0.02 & 0.23 \\
\hline
\end{tabular}

Student's paired test: ${ }^{(\dagger)} P<0.05 ;{ }^{(*)} P<0.01 ;{ }^{(\ddagger)} P<0.001 . t_{1}$ : differences between column 1 and $2 ; t_{2}$ : differences between column 3 and $4 ; t_{3}$ : differences between column 1 and 3; $t_{4}$ : differences between column 2 and 4. POPQ: International Continence Society's Pelvic Organ Prolapse Quantification system. Aa: a point located in the midline of the anterior vaginal wall $3 \mathrm{~cm}$ proximal to the external urethral meatus; Ba: the most distal position of any part of the upper anterior wall from the vaginal cuff to point Aa; C: leading edge of the cervix; D: the depth of the Douglas recession (distance between the hymen and the most distal point of the Douglas); Bp: the most distal position of any part of the upper posterior wall from the vaginal cuff to point Ap; Ap: a point located in the midline of the posterior vaginal wall $3 \mathrm{~cm}$ proximal to the hymen; gh: genital hiatus, measured from the middle of the external urethral meatus to the posterior midline hymen; pb: perineal body, measured from the posterior margin of the genital hiatus to the midanal opening; tvl (total vaginal length): the greatest depth of the vagina in centimeters, that is, the distance between hymen and point $\mathrm{D}$.

anatomic landmarks. Mantel-Haenszel's $\chi^{2}$ test was used for comparing the demographic data and urodynamic parameters according to the following formula:

$$
\chi^{2}=\frac{n([A D-B C]-(n / 2))^{2}}{(A+B)(C+D)(A+C)(B+D)} .
$$

\section{Results}

There were some significant differences in demographic data. So, USIGPg had longer duration of postmenopausal age $(P<0.01)$. Regarding the occupation in USIGPg farmers and retired persons dominated $(P<0.05 ; P<0.001$, resp.), but in USIg there were more factory workers and clerk/teachers $(P<0.05 ; P<0.001$, resp.) (Table 1$)$.

Regarding POPQ and its anatomic landmarks, there were differences between the groups, but also into the same group during VM versus RP (Table 2): (1) point Aa, which is bladder neck $(\mathrm{BN})$ projection on the anterior vaginal wall, was situated higher in RP, but moved significantly lower during VM in USIg versus USIGPg $(P<0.05)$; (2) point $\mathrm{C}$, which represents the leading edge of cervix, was situated significantly lower in RP, but especially during VM in USIGPg versus USIg $(P<0.001 ; P<0.001$, resp.); (3) the total vaginal length (tvl) was significantly greater in USIg versus USIGPg in RP $(P<0.05)$.

We analyzed the results of MT into the groups. In USIg, we found the following: (1) positive MT only in upright position in $15.15 \%$ of cases; (2) positive MT in lithotomic and upright position in $77.27 \%$ of cases; (3) positive MT in all three positions in only $7.58 \%$ of patients; (4) in up to $92.24 \%$ of patients, MT became negative during CRM, as a prognostic sign for good postoperative results. In USIGP(A), we found the following: (1) positive MT in lithotomic and 
TABLE 3: Results of the Marshall coughing test during lithotomic position, lithotomic position with cervix reposition, and upright position in USIg $(n=132)$ and USIGPg $(n=136)$ : USIGP(A) with stage I GP $(n=78)$ and USIGP(B) with stage II GP $(n=58)$.

\begin{tabular}{|c|c|c|c|c|}
\hline Study groups & $\begin{array}{l}\text { Marshall test in } \\
\text { lithotomic position }\end{array}$ & $\begin{array}{c}\text { Marshall test } \\
\text { with CRM }\end{array}$ & $\begin{array}{l}\text { Marshall test in } \\
\text { upright position }\end{array}$ & Total (\%) \\
\hline \multirow{6}{*}{$\operatorname{USIg}(n=132)$} & $(+)$ & $(-)$ & $(-)$ & $0.0 \%$ \\
\hline & $(+)$ & $(+)$ & $(-)$ & $0.0 \%$ \\
\hline & $(+)$ & $(+)$ & $(+)$ & 10/132 (7.58\%) \\
\hline & $(-)$ & $(+)$ & $(+)$ & $0.0 \%$ \\
\hline & $(-)$ & $(-)$ & $(+)$ & $20 / 132(15.15 \%)$ \\
\hline & $(+)$ & $(-)$ & $(+)$ & $102 / 132(77.27 \%)$ \\
\hline \multirow{6}{*}{$\begin{array}{l}\text { USIGP (A) with GP stage I } \\
(n=78)\end{array}$} & $(+)$ & $(-)$ & $(-)$ & $0.0 \%$ \\
\hline & $(+)$ & $(+)$ & $(-)$ & $0.0 \%$ \\
\hline & $(+)$ & $(+)$ & $(+)$ & $3 / 78(3.85 \%)$ \\
\hline & $(-)$ & $(+)$ & $(+)$ & $0.0 \%$ \\
\hline & $(-)$ & $(-)$ & $(+)$ & $5 / 78(6.41 \%)$ \\
\hline & $(+)$ & $(-)$ & $(+)$ & $70 / 78(89.74 \%) \%)$ \\
\hline \multirow{6}{*}{$\begin{array}{l}\text { USIGP (B) with GP stage II } \\
(n=58)\end{array}$} & $(+)$ & $(-)$ & $(-)$ & $8 / 58(13.79 \%)$ \\
\hline & $(+)$ & $(+)$ & $(-)$ & $0.0 \%$ \\
\hline & $(+)$ & $(+)$ & $(+)$ & $0.0 \%$ \\
\hline & $(-)$ & $(+)$ & $(+)$ & $0.0 \%$ \\
\hline & $(-)$ & $(-)$ & $(+)$ & $20 / 58(34.48 \%)$ \\
\hline & $(-)$ & $(+)$ & $(-)$ & $30 / 58(51.72 \%)$ \\
\hline
\end{tabular}

TABLE 4: Differences among the groups regarding the presence of USI during MT in all three positions.

\begin{tabular}{|c|c|c|c|c|c|c|}
\hline \multirow{3}{*}{$(+) \mathrm{MT}$} & USIg & USIGP(A) & USIGP(B) & \multirow[b]{3}{*}{$1-2$} & \multicolumn{2}{|l|}{$\chi^{2}$} \\
\hline & $\begin{array}{c}\text { GP stage } 0 \\
(n=132)\end{array}$ & $\begin{array}{l}\text { GP stage } \\
\mathrm{I}(n=78)\end{array}$ & $\begin{array}{l}\text { GP stage II } \\
(n=58)\end{array}$ & & & \\
\hline & $(1)$ & (2) & (3) & & $1-3$ & $2-3$ \\
\hline USI in lithotomic position & $112 / 13284.85 \%$ & $73 / 7893.60 \%$ & $28 / 5848.28 \%$ & 0.69 & $25.92^{\ddagger}$ & $38.34^{\ddagger}$ \\
\hline \multirow{2}{*}{ USI with CRM } & $10 / 132$ & $3 / 78$ & $30 / 58$ & 0.64 & $49.91^{\ddagger}$ & $4.23^{\ddagger}$ \\
\hline & $7.57 \%$ & $3.85 \%$ & $51.72 \%$ & & & \\
\hline \multirow{2}{*}{ USI in upright } & $132 / 132$ & $78 / 78$ & $20 / 68$ & 0.00 & $103.97^{\ddagger}$ & $67.79^{\ddagger}$ \\
\hline & $100.00 \%$ & $100.00 \%$ & $34.48 \%$ & & & \\
\hline
\end{tabular}

Mantel-Haenszel's $\chi^{2}$ test with df of $1:{ }^{(\ddagger)} P<0.001$. POPQ: International Continence Society’s Pelvic Organ Prolapse Quantification system. Stage 0: point $\mathrm{Aa}, \mathrm{Ba}, \mathrm{Bp}$, and $\mathrm{Ap}$ at the level $(-3)$, point $\mathrm{C}$ at the level (tvl-2); stage I: the most distal portion of the prolapse is $>1 \mathrm{~cm}$ above the hymen; stage II: the most distal portion of the prolapse is less or equal to $1 \mathrm{~cm}$ proximal to or distal to the plane of the hymen.

upright position in $89.74 \%$ of cases; (2) positive MT in all three positions in $3.85 \%$ of cases; (3) positive MT only in upright position in only $6.41 \%$ of patients; (4) up to in $96.15 \%$ of patients, MT became negative during CRM, as a prognostic sign for good postoperative results. In USIGP(B) we found the following: (1) positive MT in lithotomic and upright position in $34.48 \%$ of cases; (2) positive MT only in lithotomic position in $13.79 \%$ of cases; (3) up to in $51.72 \%$ of patients, MT became positive only during CRM, as a prognostic sign for poor postoperative results after the correction of GP that is, for great possibility of de novo USI (Table 3).

In Table 4 we represent the differences among the groups regarding the presence of USI during the three positions: (1) USI was more frequent in USIg and USIGP(A) versus USIGP(B) in lithotomic position $(P<0.001 ; P<0.001$, resp.) and in upright position $(P<0.001 ; P<0.001$, resp.); (2) USI was more frequent in USIGP $(B)$ versus USIg and USIGP(A) during CRM $(P<0.001 ; P<0.001$, resp.).

In Table 5 we represent the differences among the groups regarding the division of patients with different combinations of MT in the three positions. So (1) positive MT in all three positions was more frequent in USIg versus USIGP(B) $(P<0.05)$; (2) positive MT only in upright position (perhaps due to vertical pelvic organ position) was more frequent in USIg versus USIGP(B) $(P<0.01)$; $(3)$ positive MT only in lithotomic position was significantly less frequent in USIg versus USIGP(A) and USIGP(B) $(P<0.001 ; P<0.001$, resp.); (3) negative MT only with CRM in favor of excellent chances for postoperative success was more frequent in USIGP(A) versus USIg $(P<0.01)$, but also less frequent in USIGP(B) versus USIg and USIGP(A) $(P<0.001 ; P<0.001$, 
TABle 5: Differences among the groups regarding the division of patients and different combinations of the Marshall coughing test during the three positions.

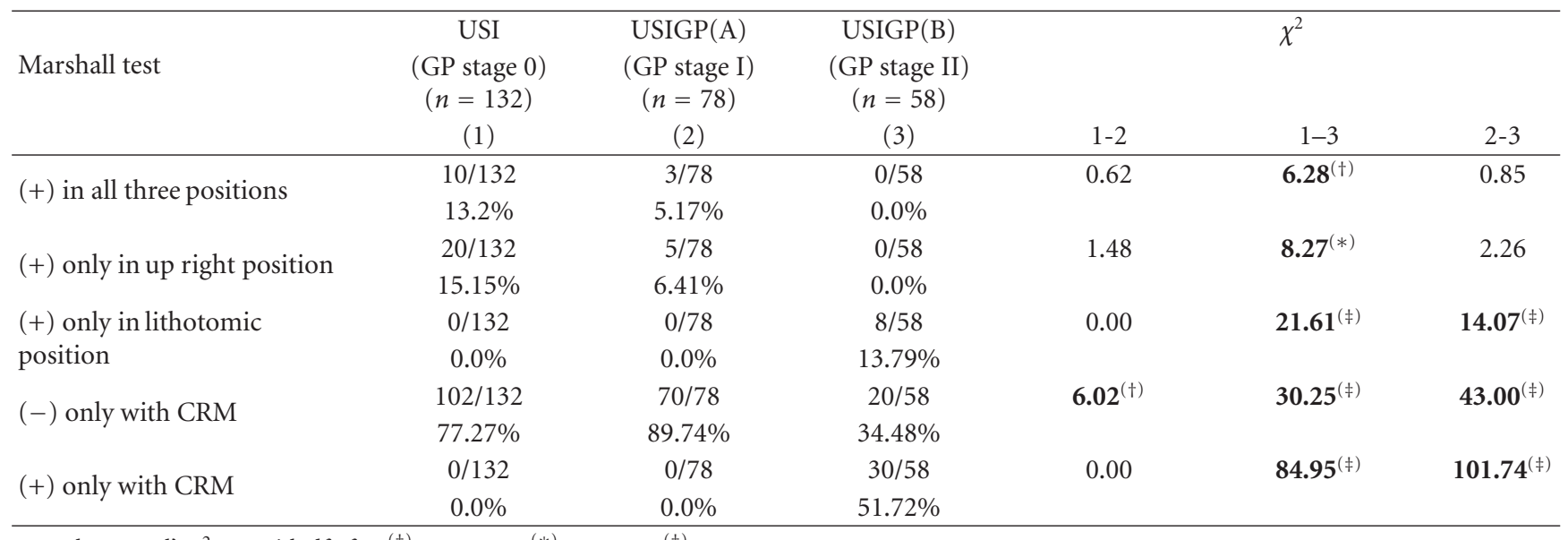

Mantel-Haenzel's $\chi^{2}$ test with df of $1:^{(\dagger)} P<0.05 ;{ }^{(*)} P<0.01 ;{ }^{(\ddagger)} P<0.001$.

resp.). These findings were in favor of USIGP(A) having the best postoperative results and USIGP(B) having the worst ones; (4) positive MT only with CRM, as a sign of occult USI, was more frequent in USIGP(B) versus USIg and USIGP(A) $(P<0.001 ; P<0.001$, resp. $)$.

In Table 6 we represent the differences in frequency of the functional symptoms according to the questionnaire/clinical examination between USIGPg and USIg. So (1) occult USI, which was evident only during CRM, predominated in USIGPg $(P<0.001)$, but genuine USI in USIg $(P<$ $0.001)$. The symptoms, such as incomplete emptying and weak stream, were also predominant in USIGPg $(P<0.001$; $P<0.001$, resp.); (2) bowel symptoms, such as flatus incontinence, urgency of defecation, discomfort with defecation, constipation, digital manipulation to finish defecation, and feeling of incomplete evacuation predominated in USIGPg (all with $P<0.001$ ); (3) sexual symptoms, such as: painful coitus, unsatisfactory coitus, decrease in orgasmic response, and incontinence during intercourse predominated in USIGPg (all with $P<0.001$ ); (4) other local symptoms, such as vaginal pressure and heaviness, awareness of tissue protrusion, low back pain, abdominal pressure, and observation or palpation of a mass, also were predominant in USIGPg (all with $P<0.001$ ).

Comparing the urodynamic analyses in both groups (Table 7), we found that positive dUPP, as a urodynamic evidence of USI, was significantly predominant in USIg $(P<$ 0.001 ), but negative dUPP, as a urodynamic evidence of absence of USI, was significantly predominant in USIGPg $(P<0.001)$. The other urodynamic parameters did not show significant differences between the groups. The urodynamic analyses in USIGPg were performed without any pessary in situ.

\section{Discussion}

(1) In USIg with present USI without GP, we noticed positive MT only in upright position in $15.15 \%$ of cases. According to the integral theory of continence of Ulmsten, Petros, and Woodman $[14,15]$, the backward forces stretch the upper vagina and bladder base backwards and downwards in a plane around the pubourethral ligament to close off the proximal urethra. We think that in patients who have positive MT only in upright position, the pelvic organs are placed in more vertical position than usual. This change in pelvic organ position perhaps is due to the changes of pelvic skeleton, such as upwards and downwards rotation of the promontorium and excessive lumbarlordosis. In this situation the backwards forces would not be enough strong to ensure a proper function of the urethra-closure mechanism that is, this mechanism does not work quite effectively. To improve the cure rate of antistress procedures, in these cases we recommend a complementary performance of procedure which would supply a horizontalisation of the vagina, for example, Young's plication of the uterosacral ligaments or sacrocolpopexy. The noted percentage of positive MT only during upright position in patients with isolated USI almost confirmed our first hypothesis.

In the same group of patients we noticed that in 7.58\% of cases, the Marshall test was positive during CRM. We value this finding as very convincing sign of future antistress surgery failure. Therefore, we recommend CRM as an obligatory part of preoperative evaluation in order to predict the postoperative failure. In presence of positive MT with CRM, a clear explanation should be given to the patient for avoiding an unpleasant postoperative surprise. As a confirmation of these, our statement is the fact that this percent, which we found as positive MT during CRP, is similar to those reported by most authors as a failure rate after anti-stress surgery $[10,19]$. The noted percentage of positive MT during CRM in patients with isolated USI gave an affirmation of our second hypothesis.

(2) In USIGP(A)s with USI and GP stage I, in up to 96.15\% (75/78), MT became negative during CRM. According to our results, in all patients with USI and GP stage I in whom positive MT became negative during CRM, we recommend a concomitant performance of an anti-stress procedure, abdominal hysterectomy, and a procedure which 
TABLE 6: Functional symptoms according to the questionnaire and clinical examination in USIGPg $(n=136)$ with GP and USI, and USIg $(n=132)$ with USI.

\begin{tabular}{|c|c|c|c|}
\hline & $\begin{array}{c}\text { USIGPg }(n=136) \\
(1)\end{array}$ & $\begin{array}{c}\text { USIg }(n=132) \\
(2)\end{array}$ & $\begin{array}{l}\chi^{2} \\
1-2\end{array}$ \\
\hline \multicolumn{4}{|c|}{ Urinary symptoms (according to the questionnaire and clinical examination (Marshall test)) } \\
\hline Potential USI (during prolapse reposition) & $33 / 136(24.3 \%)$ & $10 / 132(7.57 \%)$ & $12.61^{(\ddagger)}$ \\
\hline Genuine USI (without prolapse reposition) & $106 / 136(77.8 \%)$ & $132 / 132(100.0 \%)$ & $34.98^{(\ddagger)}$ \\
\hline Frequency & $30 / 136(22.1 \%)$ & $20 / 132(15.1 \%)$ & $1.67 \mathrm{NS}$ \\
\hline Urgency & $24 / 136(19.6 \%)$ & $29 / 132(22.0 \%)$ & $2.26 \mathrm{NS}$ \\
\hline Hesitancy & $30 / 136(22.1 \%)$ & $25 / 132(18.9 \%)$ & $0.23 \mathrm{NS}$ \\
\hline Nocturia & $19 / 136(14.0 \%)$ & $17 / 132(12.9 \%)$ & $0.03 \mathrm{NS}$ \\
\hline Incomplete emptying & $49 / 136(36.1 \%)$ & $4 / 132(3.0 \%)$ & $43.84^{(\ddagger)}$ \\
\hline Weak stream & $42 / 136(30.9 \%)$ & $4 / 132(3.0 \%)$ & $30.66^{(\ddagger)}$ \\
\hline \multicolumn{4}{|l|}{ Bowel symptoms } \\
\hline Flatus incontinence & $15 / 136(11.0 \%)$ & $0 / 132(0.0 \%)$ & $13.38^{(\ddagger)}$ \\
\hline Incontinence of liquid stool & $4 / 136(2.9 \%)$ & $0 / 132(0.0 \%)$ & $2.19 \mathrm{NS}$ \\
\hline Urgency of defecation & $19 / 136(14.0 \%)$ & $0 / 132(0.0 \%)$ & $17.75^{(\ddagger)}$ \\
\hline Discomfort with defecation & $42 / 136(30.9 \%)$ & $4 / 132(3.0 \%)$ & $30.66^{(\ddagger)}$ \\
\hline Constipation & $75 / 136(55.1 \%)$ & $25 / 132(18.9 \%)$ & $35.94^{(\ddagger)}$ \\
\hline Digital manipulation to finish defecation & $19 / 136(14.0 \%)$ & $0 / 132(0.0 \%)$ & $17.75^{(\ddagger)}$ \\
\hline Feeling of incomplete evacuation & $23 / 136(16.9 \%)$ & $4 / 132(3.0 \%)$ & $12.73^{(\ddagger)}$ \\
\hline Rectal protrusion during defecation & $11 / 136(8.9 \%)$ & $0 / 132(0.0 \%)$ & $9.15^{(*)}$ \\
\hline \multicolumn{4}{|l|}{ Sexual symptoms } \\
\hline Pain with coitus & $109 / 136(80.1 \%)$ & $21 / 132(15.9 \%)$ & $44.05^{(\ddagger)}$ \\
\hline Unsatisfactory coitus & $113 / 136(83.1 \%)$ & $12 / 132(9.1 \%)$ & $144.14^{(\ddagger)}$ \\
\hline Decrease in orgasmic response & $117 / 136(86.0 \%)$ & $49 / 132(37.1 \%)$ & $65.78^{(\ddagger)}$ \\
\hline Incontinence during the intercourse & $19 / 136(14.0 \%)$ & $45 / 132(34.1 \%)$ & $16.01^{(\ddagger)}$ \\
\hline \multicolumn{4}{|l|}{ Other local symptoms } \\
\hline Vaginal pressure and heaviness & $109 / 136(80.1 \%)$ & $0 / 132(0.0 \%)$ & $174.68^{(\ddagger)}$ \\
\hline Vaginal/perineal pain & $34 / 136(25.0 \%)$ & $4 / 132(3.0 \%)$ & $24.75^{(\ddagger)}$ \\
\hline Low back pain & $113 / 136(83.1 \%)$ & $4 / 132(3.0 \%)$ & $170.97^{(\ddagger)}$ \\
\hline Abdominal & $106 / 136(77.9 \%)$ & $8 / 132(6.1 \%)$ & $144.00^{(\ddagger)}$ \\
\hline
\end{tabular}

Mantel-Haenszel's $\chi^{2}$ test with df of $\left.1:{ }^{(\dagger)} P<0.05 ; \quad{ }^{*}\right) P<0.01 ; \quad{ }^{(\ddagger)} P<0.001$.

TABLE 7: Urodynamic analyses in USIGPg group $(n=136)$ with GP and USI, and USIg $(n=132)$ with USI.

\begin{tabular}{|c|c|c|c|}
\hline Urodynamic parameters & $\begin{array}{l}\operatorname{USIGPg}(n=136) \\
(1)\end{array}$ & $\begin{array}{l}\operatorname{USIg}(n=132) \\
(2)\end{array}$ & $\begin{array}{l}\chi^{2} \\
1-2\end{array}$ \\
\hline \multicolumn{4}{|l|}{ Cystometry } \\
\hline Detrusor instability & $38 / 136(27.9 \%)$ & $33 / 132(25.0 \%)$ & 0.16 \\
\hline Decreased capacity of the bladder & $57 / 136(41.9 \%)$ & $37 / 132(28.0 \%)$ & 5.06 \\
\hline Regular cystometry & $98 / 136(72.0 \%)$ & 99/132 (75.0\%) & 0.47 \\
\hline$U P P \max$ & $88.93 \pm 11,67$ & $90.49 \pm 14.22$ & 0.25 \\
\hline \multicolumn{4}{|l|}{ dUPP(default transmission $)$} \\
\hline $\begin{array}{l}\text { Positive dUPP (USI }(+) \text { according to the urodynamic } \\
\text { examination) }\end{array}$ & $106 / 136(77.9 \%)$ & $124 / 132(93.9 \%)$ & $15.40^{(\ddagger)}$ \\
\hline $\begin{array}{l}\text { Negative dUPP (USI (-) according to the urodynamic } \\
\text { examination) }\end{array}$ & $30 / 136(21.1 \%)$ & $8 / 132(6.10 \%)$ & $12.78^{(\ddagger)}$ \\
\hline
\end{tabular}

Mantel-Haenszel's $\chi^{2}$ test with df of $1:{ }^{(\dagger)} P<0.05 ; \quad{ }^{(*)} P<0.01$; ${ }^{(\ddagger)} P<0.001$. 
would provide a stable position of the vagina in high level, such as Young's plication of the uterosacral ligaments or sacrocolpopexy. An isolated anti-stress procedure would have short-term results, that is, an early appearance of recurrent USI and vault prolapse would happen. In these patients, the deteriorating process of pubourethral ligaments due to downwards forces produced by the uterine prolapse is already finished, but the cystocele is not large enough to mask USI in lithotomic and upright position. An isolated antistress procedure will not solve the problem, that is, stop this deteriorating process because the downwards GP forces will continue and soon will eliminate the positive postoperative results, resulting in recurrent USI and vault prolapse. Therefore, we recommend obligatory GP repair during antistress surgery in order to obtain a durable postoperative success. Costantini et al. [20], in their study of 47 women with GP and USI, divided into two groups: group A, treated with GP repair and Burch colposuspension and group B, treated only with GP repair, did not find significant intergroup difference regarding anatomical outcome, but significant intergroup differences regarding recurrent USI (in group A 13/24 patients were still incontinent compared with $9 / 23$ in group B).

The noted percentage of negative MT during CRM in patients with USI and GP stage I of our study slightly exceeded our expectation in the third hypothesis.

(3) In USIGP(B) with USI and GP stage II, we found that up to in more than half of patients, the Marshall test became positive only during CRM. This maneuver corrected the cystocele and annulated its immobilizing effect on the bladder neck, that is, allowed a complete movement downward and backward of the bladder neck and its opening during VM with consecutive USI development. The noted percentage of positive MT during CRM in patients with USI and GP stage II in our study considerably exceeded our expectation in the forth hypothesis. This is the reason why we strongly recommend CRM in preoperative evaluation of patients with stage II GP. In cases with USI and GP stage II, we always combined the vaginal hysterectomy with the anti-stress procedure: Lazarevski's suburethral vaginal duplication [21]. In these group of patients, the deteriorating process of pubourethral ligaments, due to downward GP forces, is already finished, but the cystocele is large enough to have an overall impact over the above-mentioned forces and mask USI in lithotomic/upright position. Therefore, we recommend CRM in preoperative evaluation and some anti-stress procedure during vaginal hysterectomy, in order to avoid postoperative de novo USI.

Liang et al. [22] in their study of 79 patients with severe GP, diagnosed $49 / 79(62.03 \%)$ as of the occult USi with preoperative performing the pessary test. In 32 of them, they performed TVT during vaginal hysterectomy with cure rate of USI of $90.6 \%$. In the other 17 women with occult USI, they performed only vaginal hysterectomy and noted $64.7 \%$ postoperative de novo USI. The patients with negative preoperative pessary test did not develop de novo USI. In another study done by us of 216 patients with genital prolapse: stage III/IV (POPQ), we diagnosed occult USI with CRM in $31 / 216(14.4 \%)$ and genuine USI in $12 / 216(5.56 \%)$. In all cases we systematically performed the Lazarevski's vaginal duplication as an antistress procedure during vaginal hysterectomy. At the last follow-up (mean 38.6 months), we noted only 3 recurrent USI of 31 cases with preoperative occult USI, that is, $90.32 \%$ cure rate, but also 3 recurrent USI of 12 patients with preoperative genuine USI, that is, $75 \%$ cure rate unpublished observations. Chaikin et al. [23], in 14 patients with GP and occult USI, performed pubovaginal sling and noted $14 \%$ of postsurgical USI development.

Cervix reposition maneuver could be useful arm in selection of (1) patients with isolated USI and great chance for postoperative failure; (2) patients with USI and GP stage I, who need GP repair during anti-stress surgery; (3) patients with USI and GP stage II, who need anti-stress procedure during vaginal hysterectomy.

\section{References}

[1] E. Borstad and T. Rud, "The risk of developing urinary stressincontinence after vaginal repair in continent women. A clinical and urodynamic follow-up study," Acta Obstetricia et Gynecologica Scandinavica, vol. 68, no. 6, pp. 545-549, 1989.

[2] J. J. Klutke and S. Ramos, "Urodynamic outcome after surgery for severe prolapse and potential stress incontinence," American Journal of Obstetrics and Gynecology, vol. 182, no. 6, pp. 1378-1381, 2000.

[3] D. Gordon, A. Groutz, I. Wolman, J. B. Lessing, M. P. David, and M. M. Karram, "Development of postoperative urinary stress incontinence in clinically continent patients undergoing prophylactic Kelly plication during genitourinary prolapse repair," Neurourology and Urodynamics, vol. 18, no. 3, pp. 193198, 1999.

[4] F. Lecuru, R. Taurelle, C. Clouard, and J. P. Attal, "Abdominal surgical treatment for genitourinary prolapse. Results of a continuous series of 203 operations," Annales de Chirurgie, vol. 48, no. 11, pp. 1013-1019, 1994.

[5] A. L. Milani, P. K. Flu, M. E. Vierhout, and H. C. S. Wallenburg, "Resuls and complications of vaginal; correction of vaginal and uterine prolapse with or without urinary incontinence: a prospective study," Nederlands Tijdschrift voor Geneeskunde, vol. 137, no. 5, pp. 250-255, 1993.

[6] G. W. Morley and J. O. L. DeLancey, "Sacrospinous ligament fixation for eversion of the vagina," American Journal of Obstetrics and Gynecology, vol. 158, no. 4, pp. 872-881, 1988.

[7] A. D. Hewson, "Transvaginal sacrospinous colpopexy for posthysterectomy vault prolapse," Australian and New Zealand Journal of Obstetrics and Gynaecology, vol. 38, no. 3, pp. 318324, 1998.

[8] C. Maher, B. Feiner, K. Baessler, E. J. Adams, S. Hagen, and C. M. Glazener, "Surgical management of pelvic organ prolapse in women," Cochrane Database of Systematic Reviews, no. 3, Article ID CD004014, 2010.

[9] A. G. Visco, L. Brubaker, I. Nygaard et al., "The role of preoperative urodynamic testing in stress-continent women undergoing sacrocolpopexy: the Colpopexy and Urinary Reduction Efforts (CARE) randomized surgical trial," International Urogynecology Journal and Pelvic Floor Dysfunction, vol. 19, no. 5, pp. 607-614, 2008.

[10] M. Bandarian, Z. Ghanbari, and A. Asgari, "Comparison of transobturator tape (TOT) vs Burch method in treatment of 
stress urinary incontinence," Journal of Obstetrics and Gynaecology, vol. 31, no. 6, pp. 518-520, 2011.

[11] M. T. Martínez-Fornés, C. F. Pérez, C. F. López, C. F. Lucas, and J. B. Hernando, "A three year follow-up of a prospective open randomized trial to compare tension-free vaginal tape with Burch colposuspension for treatment of female stress incontinence," Actas Urologicas Espanolas, vol. 33, no. 10, pp. 1088-1096, 2009.

[12] J. H. Hong, M. S. Choo, and K. S. Lee, "Long-term results of laparoscopic burch colposuspension for stress urinary incontinence in women," Journal of Korean Medical Science, vol. 24, no. 6, pp. 1182-1186, 2009.

[13] M. C. M. Lapitan, J. D. Cody, and A. Grant, "Open retropubic colposuspension for urinary incontinence in women: a short version cochrane review," Neurourology and Urodynamics, vol. 28, no. 6, pp. 472-480, 2009.

[14] P. E. Petros and U. I. Ulmsten, "An integral theory and its method for the diagnosis and management of female urinary incontinence," Acta Obstetricia et Gynecologica ScandinavicaSupplement, vol. 153, pp. 69-70, 1990.

[15] P. E. P. Petros and P. J. Woodman, "The integral theory of continence," International Urogynecology Journal and Pelvic Floor Dysfunction, vol. 19, no. 1, pp. 35-40, 2008.

[16] R. C. Bump, A. Mattiasson, K. Bo et al., "The standardization of terminology of female pelvic organ prolapse and pelvic floor dysfunction," American Journal of Obstetrics and Gynecology, vol. 175, no. 1, pp. 10-17, 1996.

[17] D. Moher, K. F. Schulz, D. G. Altman, and L. Lepage, "The CONSORT statement: revised recommendations for improving the quality of reports of parallel-group randomised trials," The Lancet, vol. 357, no. 9263, pp. 1191-1194, 2001.

[18] P. Abrams, L. Cardozo, M. Fall et al., "The standardisation of terminology of lower urinary tract function: report from the standardisation sub-committee of the international continence society," Neurourology and Urodynamics, vol. 21, no. 2, pp. 167-178, 2002.

[19] M. C. M. Lapitan, J. D. Cody, and A. Grant, "Open retropubic colposuspension for urinary incontinence in women," Cochrane Database of Systematic Reviews, no. 2, Article ID CD002912, 2009.

[20] E. Costantini, M. Lazzeri, V. Bini, M. Del Zingaro, A. Zucchi, and M. Porena, "Burch colposuspension does not provide any additional benefit to pelvic organ prolapse repair in patients with urinary incontinence: a randomized surgical trial," Journal of Urology, vol. 180, no. 3, pp. 1007-1012, 2008.

[21] M. B. Lazarevski, "Suburethral duplication of the vaginal wall: an original operation for urinary stress incontinence in women," International Urogynecology Journal and Pelvic Floor Dysfunction, vol. 6, no. 2, pp. 73-79, 1995.

[22] C.-C. Liang, Y.-L. Chang, S.-D. Chang, T.-S. Lo, and Y.-K. Soong, "Pessary test to predict postoperative urinary incontinence in women undergoing hysterectomy for prolapse," Obstetrics and Gynecology, vol. 104, no. 4, pp. 795-800, 2004.

[23] D. C. Chaikin, A. Groutz, and J. G. Blaivas, "Predicting the need for anti-incontinence surgery in continent women undergoing repair of severe urogenital prolapse," Journal of Urology, vol. 163, no. 2, pp. 531-534, 2000. 


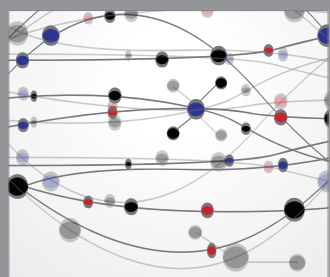

The Scientific World Journal
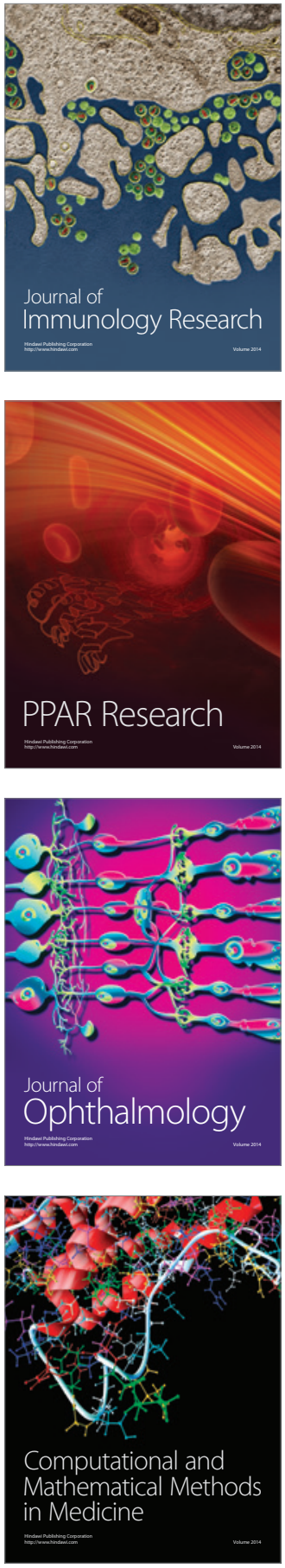

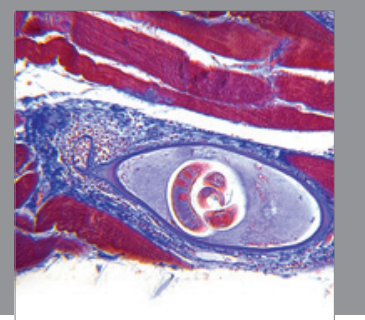

Gastroenterology

Research and Practice
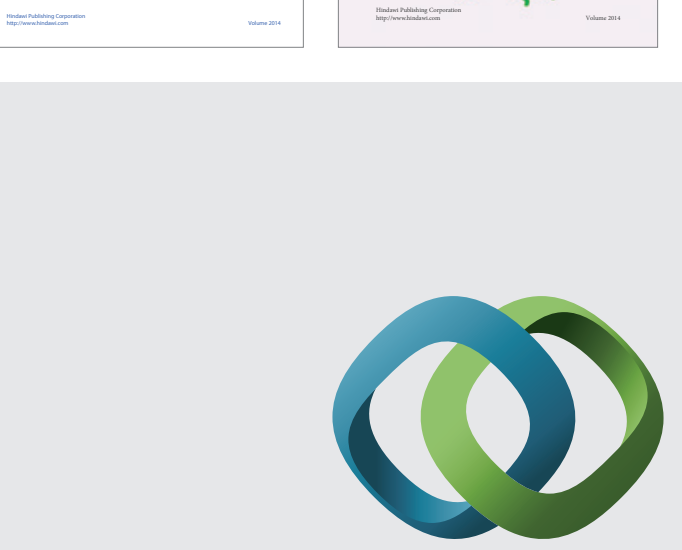

\section{Hindawi}

Submit your manuscripts at

http://www.hindawi.com
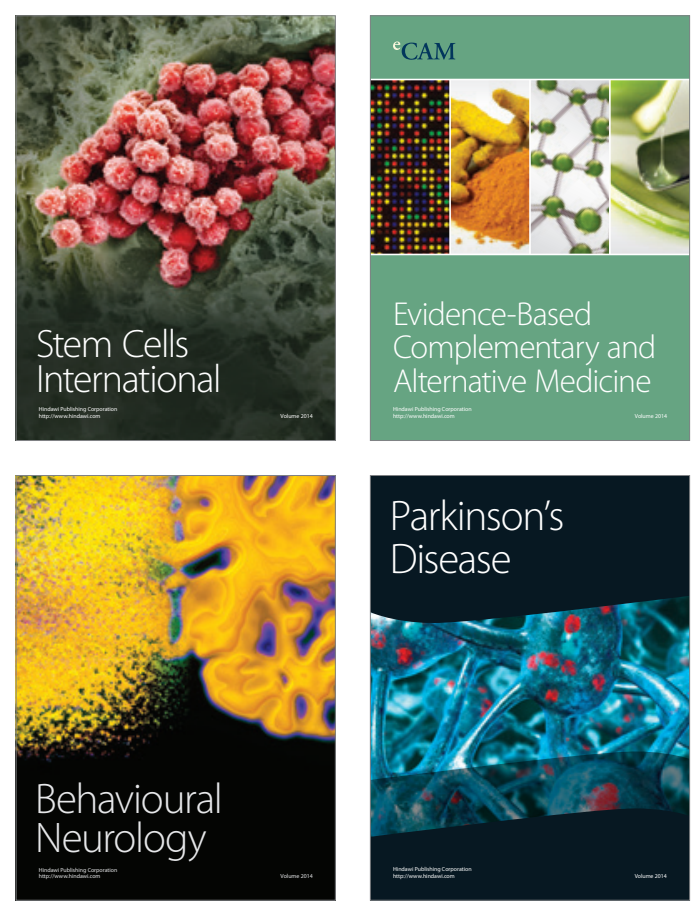

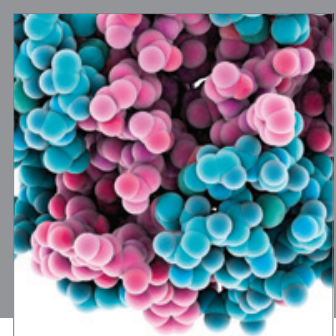

Journal of
Diabetes Research

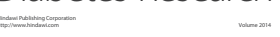

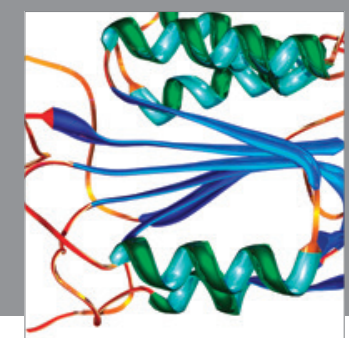

Disease Markers
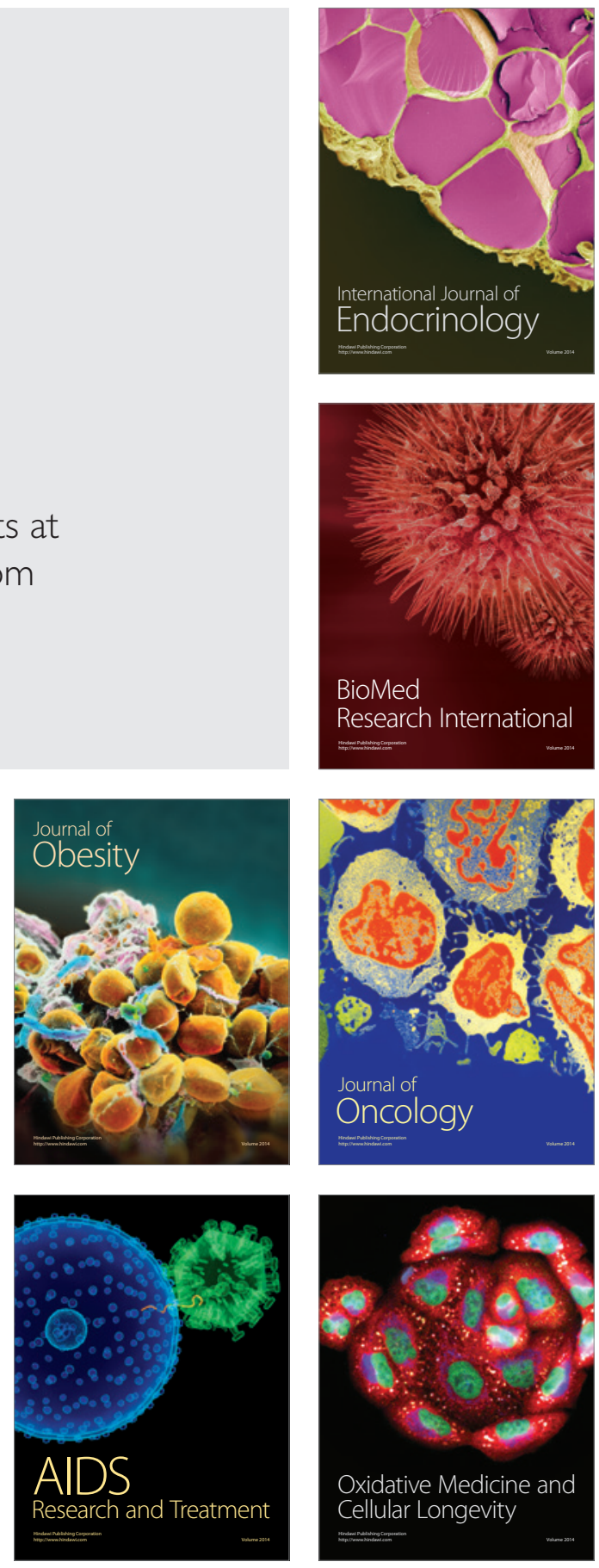